\title{
EFFECT OF METALLIC-COATING PROPERTIES ON THE TRIBOLOGY OF COATED AND OIL-LUBRICATED CERAMICS*
}

O. O. Ajayi, A. Erdemir, G. R. Fenske, R. A. Erck, J.-H. Hsieh, and F. A. Nichols

Materials and Components Technology Division

Argonne National Laboratory

$\mathrm{ANL} / \mathrm{MCT} / \mathrm{CP}--77794$

Argonne, IL 60439 USA

DE93 010663

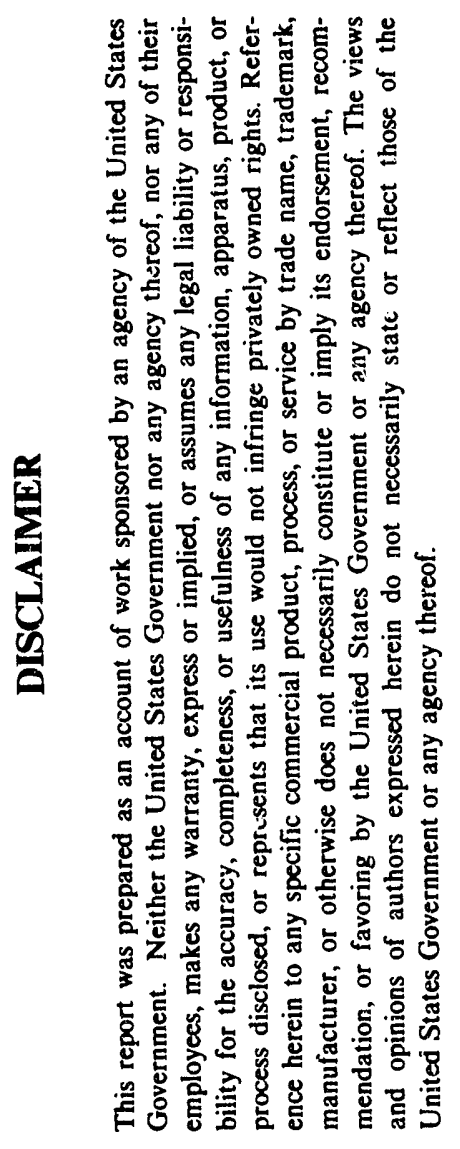

September 1992

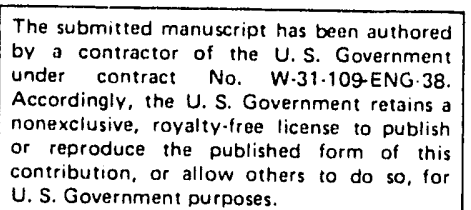

allow others torm of this

For presentation at the 1993 STLE Annual Meeting, Calgary, Canada, May 17-20.

*Work supported by the Tribology Program, Office of Transportation Materials, U.S.

Department of Energy, under Contract W-31-109-Eng-38. 


\section{EFFECT OF METALLIC-COATING PROPERTIES ON THE TRIBOLOGY OF COATED AND OIL-LUBRICATED CERAMICS*}

O. O. Ajayi, A. Erdemir, G. R. Fenske, R. A. Erck, J.-H. Hsieh, and F. A. Nichols Materials and Components Technology Division

Argonne National Laboratory

Argonne, Illinois 60439

\section{ABSTRACT}

Friction and wear behavior was determined for zirconia ceramics lubricated with solid coatings ( $\mathrm{Ag}, \mathrm{Au}$, and $\mathrm{Nb}$ ) deposited by ion-beam-assisted-deposition (IBAD) techniques, and a polyol-ester-based synthetic oil. Although the use of soft $\mathrm{Ag}$ and Au coatings as solid lubricants in conjunction with the synthetic oil significantly reduced the friction and wear under boundary lubrication at temperatures up to $250^{\circ} \mathrm{C}$, these films had poor durability. In contrast,the $\mathrm{Nb}$ coating was more durable (in terms of chemical reactivity and adhesion during the tribo-tests) than were the $\mathrm{Ag}$ or Au films. However, the friction and wear behavior of the $\mathrm{Nb}$-coated zirconia was poorer than that of the ceramics coated with $\mathrm{Ag}$ or $\mathrm{Au}$.

\section{INTRODUCTION}

Ceramics are being considered for high-temperature applications where their excellent strength and chemical stability are desirable [1-4]. In some applications, such as low-heat-rejection engines, some ceramic components will be in sliding contact with other components and it is therefore important to consider their tribological properties. However, the tribological properties of many ceramics are quite poor when

\footnotetext{
* Work supported by the Tribology Program, Office of Transportation Materials, U.S. Department of Energy, under Contract W-31-109-Eng-38
} 
compared to the behavior of materials commonly in use at lower temperatures $[5,6]$. Advanced liquid lubricants are under development, but it may prove necessary (particularly under boundary-lubrication regimes) to use solid lubricants in conjunction with liquid lubrication.

Recent results indicate that soft metallic films deposited on ceramic substrates by ion-beam-assisted-deposition (IBAD) techniques can significantly reduce friction and wear at elevated temperatures under dry sliding conditions[7,8]. Good results were also obtained during the initial stages of liquid-lubricated wear tests performed on IBAD Ag-coated ceramics; however, reactions with sulfur-bearing oil additives eventually lead to delamination of the $\mathrm{Ag}$ films [9].

Consequently, the series of tests reported here was performed to determine whether coatings of a highly reactive element $(\mathrm{Nb})$ or a noble element $(\mathrm{Au})$ would perform comparably to $\mathrm{Ag}$, yet remain intact for longer periods of time.

\section{EXPERIMENTAL DETAILS}

Friction and wear tests were done with pin-on-flat contact geometry in reciprocating sliding. The pins ( $8 \mathrm{~mm}$ in diameter and $15 \mathrm{~mm}$ long) were rounded at one end to a $127-\mathrm{mm}$ radius of curvature. Details of the test device were described previously [10]; tests were conducted at a normal load of $50 \mathrm{~N}$, reciprocating frequency of $1 \mathrm{~Hz}$, and a stroke length of $25 \mathrm{~mm}$; this resulted in an average sliding speed of $0.05 \mathrm{~ms}^{-1}$ for a total of 2000 cycles. Three temperatures were used: $23^{\circ} \mathrm{C}$ (room temperature), $150^{\circ} \mathrm{C}$, and $250^{\circ} \mathrm{C}$. The $50-\mathrm{N}$ normal load produced an initial mean Hertzian pressure of about $208 \mathrm{MPa}$ for $\mathrm{ZrO}_{2}-\mathrm{on}-\mathrm{ZrO}_{2}$ contact. The nominal bearing pressure is known to decrease very rapidly once wear begins, due to the change in contact area because of 
wear [8]. A set of tests was conducted under dry conditions and without any metal coatings at the three temperatures to provide a reference to which the effectiveness of the lubricants can be compared. For the high-temperature dry tests, both the flat and pin specimens were heated to the required temperature. The oil-lubricated tests were coducted using uncoated, Ag-coated, Au-coated and $\mathrm{Nb}$-coated flats. A $100 \%$ polyolester-based synthetic oil with a proprietary blend of additives was used. The lubricant was applied by immersing the flat specimen in a bath of the oil during the test, creating a fully flooded contact. The high-temperature tests were done by heating the oil bath and the pin specimens to the desired temperature.

The friction coefficient was continuously monitored in all tests by a strain-gauge device. Pin wear was calculated from the dimensions of the wear scar measured by an optical microscope. Wear volume in the pin was estimated by $V_{p}=\left(\pi r^{4}\right) / 4 R$, where $r$ is the wear-scar radius and $R$ is the radius of curvature [11]. The tests were stopped after 500, 1000, and 2000 cycles and the pin wear-scar dimensions were measured; from these measurements, specific wear rate in the pin can be determined as a function of the number of cycles. "Instantaneous" specific wear rate was calculated from the average rate for each range of test cycles as $\Delta V /\left(F_{n} \Delta S\right)$, where $\Delta V$ is the change in the wear volume in that range, $F_{n}$ is the applied normal force, and $\Delta S$ is the incremental sliding distance.

The worn surfaces of the pin and the flat were examined by optical and scanning electron microscopes (SEM) equipped with an X-ray energy-dispersive spectrometer (EDS) and a wavelengthi-dispersive spectrometer (WDS). The pin and uncoated flat specimens were sputter-coated with a thin layer of carbon before examination to prevent charging during the SEM analysis. 


\section{RESULTS AND DISCUSSION}

Frictional behavior under the various test conditions is shown in Fig. 1. For $\mathrm{ZrO}_{2}$ sliding pairs with no metallic coating (solid lubricant) or oil lubricant, sliding began in all cases with a relatively low friction coefficient of 0.15 , but increased gradually to a higher steady value. The rate at which the steady friction was attained and the value of the friction coefficient depended on the ambient test temperature. At room temperature, the steady friction coefficient of about 0.65 was attained after about 1000 cycles of sliding. At 150 and $250^{\circ} \mathrm{C}$, the steady friction value was slightly lower and was attained after 700 and 100 cycles of sliding respectively. The initial low friction coefficient may be due to surface contamination and/or adsorption of various species from the test environment onto the surface. The "contaminant" is then gradually removed by the sliding contact; removal is accelerated by thermal desorption as the temperature is increased, and thus the friction coefficient reached its steady value faster at higher temperatures.

For uncoated $\mathrm{ZrO}_{2}$ with oil lubrication, the friction coefficient was nearly constant at about 0.16 throughout the test duration at the three test temperatures. This is because all test conditions were within the boundary-lubrication regime, as shown by the film thickness calculations [9]. The friction coefficient range of $0.10-0.25$ is typical for the boundary-lubrication regime.

When the oil lubricant was applied to the metal-coated ceramics, the frictional behavior was strongly dependent on the mechanical properties of the coating material. With all coated and oil-lubricated tests at room temperature (Fig. 1a), sliding began with a friction coefficient of 0.14 . However, with the soft metals ( $\mathrm{Au}$ and $\mathrm{Ag}$ ), friction decreased gradually during the first 500 cycles to a steady value of 0.05 , while with $\mathrm{Nb}$ (which is harder), the friction coefficient remained unchanged at about 0.14 throughout 
the duration of the tests. This value was only slightly lower than the 0.16 of the uncoated, oil-lubricated test. Scanning electron microscope (SEM) micrographs elucidated the reasons for these differences. On the surface of the soft coating (Fig. 2), a very smooth contact area, with little or no evidence of wear, was generated. This has the effect of increasing the I ratio, defined as the ratio of lubricant film thickness $(h)$ to the composite surface roughness (s) of the two contacting surfaces [12]. The result is the formation and maintenance of a fluid film between the two sliding surfaces, so that the test that began under the boundary-lubrication regime could eventually have a continuous fluid film at the interface. The decrease in friction to a steady value is thus associated with the smoothing of the soft film.

For the harder $\mathrm{Nb}$ coating, no significant smoothing of the contact area was observed (Fig. 3). Instead, wearing of the coating occurred, with debris consisting primarily of $\mathrm{Nb}$ (according to EDS analysis) observed on the surface (Fig. 3a). In all the tests, the Nb coating was not worn through as shown by $\mathrm{Nb}$ mapping (Fig. 3b). The lack of a decrease in surface roughness of the Nb coating ensures that the boundary-lubrication conditions was maintained and that appreciable direct contact between the pin and the coating occurred during the entire test, resulting in the coating wear. Boundary lubrication accounted for the constant friction coefficient in the uncoated and $\mathrm{Nb}$-coated oil-lubricated tests. At higher temperatures of $150^{\circ}$ and $250^{\circ} \mathrm{C}$, the $\mathrm{Nb}$ coating was more effective in reducing friction than at room temperature (Figs. $1 \mathrm{~b}$ and $1 \mathrm{C}$ ). In fact, at $250^{\circ} \mathrm{C}$, the steady-state friction coefficient in the $\mathrm{Nb}$-coated and oil-lubricated tests was about 0.06 , substantially lower than the room-temperature value. With the soft films, however, only a slight friction decrease was observed with increasing temperature.

Upon prolonged exposure to the oil, failure of $\mathrm{Ag}$ was observed details of which were described previously [9]. Although the detailed mechanism of this film 
delamination is not yet understood, it appears to involve the diffusion of $S$ additives from oil lubricant to the coating/substrate interface, thereby weakening it. For the $\mathrm{Au}$ coating poor adhesion to the $\mathrm{ZrO}_{2}$ substrate also led to poor durability. The coatings failure occurred more quickly at higher temperatures. Failure of the coating was the cause of the increased friction coefficient in the Ag-coated test at $250^{\circ} \mathrm{C}$ (Fig. 1C) to the same level as that of the uncoated flat. Nb coatings, on the other hand, remained wellbonded to the $\mathrm{ZrO}_{2}$ substrate during the duration of all the tests, even though coating removal by a continuous-wear process was occurring. These differences in coating adherence are due to differences in the reactivity of the $\mathrm{Ag}, \mathrm{Au}$, and $\mathrm{Nb}$. The lessreactive $\mathrm{Ag}$ and $\mathrm{Au}$ metals could not benefit from the possible enhancement of adhesion through chemical interaction at the coating/substrate interface. The morereactive $\mathrm{Nb}$ appeared to have benefited from such interaction, resulting in its superior adhesion and durability. Furthermore, chemical interactions between the $\mathrm{Ag}$ and the $S$ additives in the synthetic oil were detrimental to the durability of the Ag coatings.

In all oil-lubricated tests, there was no measurable wear in the $\mathrm{ZrO}_{2}$ flats. With the $\mathrm{Nb}$ coatings, however, wear occurred but the coating was not worn through. With the $\mathrm{Ag}$ and Au coatings, only plastic flow occurred in the coating layer and there was no material removal. In some cases, however, these soft coatings failed by delamination at the coating/substrate interface, as mentioned above. Variation of the "instantaneous" specific wear rates in the mating $\mathrm{ZrO}_{2}$ pins is shown in Fig. 4. At room temperature (Fig. 4a), the pin specific wear rate under dry conditions sliding against an uncoated flat averaged about $10^{-5} \mathrm{~mm}^{3} \mathrm{~N}^{-1} \mathrm{~m}^{-1}$ and increased continuously with the number of sliding cycles (from $2 \times 10^{-6}$ to $3 \times 10^{-5} \mathrm{~mm}^{3} \mathrm{~N}^{-1} \mathrm{~m}^{-1}$ ). With oil lubrication, but uncoated, the pin specific wear rate was reduced by about three orders of magnitude to about $10^{-8} \mathrm{~mm}^{3} \mathrm{~N}^{-1} \mathrm{~m}^{-1}$ and showed a slight decrease with number of cycles. For oil-lubricated and metal-coated flats, pin wear behavior was strongly 
influenced by the mechanical properties of the coating material just as was the friction. With the relatively soft $\mathrm{Ag}$ and $\mathrm{Au}$ coatings, there was no measurable wear in the pin during the tests. For the $\mathrm{Nb}$ coating, pin wear was significant. $\left(\approx 10^{-7} \mathrm{~mm}^{3} \mathrm{~N}^{-1} \mathrm{~m}^{-1}\right)$. The difference was due to deformation of the soft metal coatings, which increased the I ratio and prevented direct contact between the pin and the flat. For $\mathrm{Nb}$, the I ratio remained unchanged and thus there was continuous interaction between the flat and the pin surfaces, leading to the wear, mentioned earlier.

At $150^{\circ}$ and $250^{\circ} \mathrm{C}$ (Figs. $4 \mathrm{~b}$ and $4 \mathrm{c}$ ), the pin wear rate reflected changes in the proerties of the oil and the coatings. At $150^{\circ}$ and $250^{\circ} \mathrm{C}$, there was a substantial increase in the wear rate of the pin sliding on the uncoated flat relative to that at room temperature. This was due primarily to decreased oil viscosity which led to more intimate contact between the sliding surfaces. The accelerated failure of the film at higher temperatures, particularly with Ag coatings, resulted in measurable wear. This was more pronounced at $250^{\circ} \mathrm{C}$, where the "instantaneous" wear rate at the end of the test was comparable to that of the uncoated flat. This was due to the early failure of the film; recall that a similar behavior was observed for the friction coefficient.

The results presented above indicate that although the $\mathrm{Ag}$ and $\mathrm{Au}$ films had low wear rates and friction, their use was limited by chemical interaction with oil additives that eventually led to coating delamination. Conversely, the $\mathrm{Nb}$ coatings remained bonded to the substrate but suffered from higher friction and wear rates. A plausible solution to these problems could be achieved by combining the benefits of each coating type through multilayer coating. Conceivably, $\mathrm{Nb}$ could be deposited first onto the $\mathrm{ZrO}_{2}$ and then $\mathrm{Ag}$ or Au could be deposited on the $\mathrm{Nb}$. Such a multilayer coating should have the good adhesion of $\mathrm{Nb}$ to $\mathrm{ZrO}_{2}$ and the plasticity of the soft top layer. Study of this multilayer-coating approach is underway. 


\section{CONCLUSIONS}

Results of the present study show that simultaneous application of a solid lubricant (in the form of a thin metallic film) and liquid lubricant (synthetic oil) provides effective lubrication for $\mathrm{ZrO}_{2}$ under boundary-lubrication conditions. Both the friction coefficient and wear rate were substantially reduced by this method. Soft metals ( $\mathrm{Ag}$ and $\mathrm{Au}$ ) were found to be particularly effective because they can easily deform and thus modify the lubrication regime; however, their poor reactivity did not help their adhesion to the $\mathrm{ZrO}_{2}$ substrate materials. On the other hand, the relatively hard $\mathrm{Nb}$ coating was not as effective in reducing friction and wear as were the soft films, particularly at room temperature. The higher chemical reactivity of the $\mathrm{Nb}$, however, resulted in its strong bonding to the substrate in all cases, while the less-reactive $\mathrm{Ag}$ and $\mathrm{Au}$ coatings were prone to delamination at the coating/substrate interface. At higher temperatures, due to a decrease in hardness, the coatings performed better, although the durability of the soft coatings was reduced further due to poor adhesion.

\section{REFERENCES}

(1) "Tribology of Ceramics", National Materials Advisory Board Report NMAB-435, (1988), (National Academy Press), Defense Technical Information Center, Alexandria, VA.

(2) Lackey W. J., Stinton D. P., Cerny G. A., Fehrenbacher L. L., and Schaffhauser A. C., "Ceramic Coatings for Heat Engine Materials - Status and Future Needs", Oak Ridge National Laboratory Report ORNL/TM-8959, (1984). 
(3) Proceedings of the 26th Automotive Technology Development Contractors' Coordination Meeting, P-219, October 24-27, 1988, Dearborn Ml (published by SAE, Inc., Warrendale, PA, 1989).

(4) Proceedings of 1987 Coatings for Advanced Heat Engines Workshop, July 2730, 1987, Castine, ME, CONF-870762, NTIS, Springfield, VA (1988)

(5) Dufrane, K. F. "Dynamic Contact of Ceramics", pg. IV-103 in Ref. 4.

(6) Dufrane K. F. and Gaydos, P. A. "Dynamic Contact of Ceramics in Ring-Cylinder Applications", pg. 145 in Ref. 3.

(7) Erdemir, A., Busch, D. E., Erck, R. A., Fenske, G. R., and Lee, R. "Ion-BeamAssisted Deposition of Silver Films on Zirconia Ceramics for Improved Tribological Behavior", Lubrication Engineering, Vol. 47, pp 863-872, (1991).

(8) Ajayi, O. O., Erdemir, A., Erck, R. A., Fenske, G. R., and Nichols, F. A. "The Role of Soft (metallic) Films in the Tribological Behavior of Ceramic Materials", Wear, vol. 149, pp 221-232, (1991).

(9) Ajayi, O.O., Erdemir, A., Hsieh, J.-H., Erck R.A., and Fenske, G.R. "Combined Solid and Liquid Lubrication of Silicon Nitride under Boundary Conditions", Lubrication Engineering, vol. 48, pp 584-591 (1992).

(10) Erdemir, A., Ajayi, O. O., Fenske, G. R., Erck, R. A., and Hsieh, J.-H. "The Synergistic Effect of Solid and Liquid Lubrication on Tribological Behavior of $\mathrm{ZrO}_{2}$ ", STLE Tribology Transactions, vol. 35 pp 287-297 (1992).

(11) ASTM Handbook of Standards; Vol. 03.02 G 99.

(12)Czichos H. : Tribology, Elsevier, Amsterdam (1978) P. 163. 


\section{CAPTIONFORFIGURES}

Figure 1: Variation of friction coefficient with the number of cycles for $\mathrm{ZrO}_{2}$ sliding on $\mathrm{ZrO}_{2}$ under various test conditions at (a) room temperature, (b) $150^{\circ} \mathrm{C}$, and (c) $250^{\circ} \mathrm{C}$.

Figure 2: SEM micrograph of wear track on Ag-coated $\mathrm{ZrO}_{2}$ flat after oil-lubricated test, showing smoothing of the contact area.

Figure 3: SEM micrograph of wear track in oil-lubricated $\mathrm{Nb}$-coated $\mathrm{ZrO}_{2}$ flats showing (a) wear of $\mathrm{Nb}$ coatings and (b) EDS map of $\mathrm{Nb}$ indicating that film has not been worn through.

Figure 4: Variation of "instantaneous" specific wear rate of $\mathrm{ZrO}_{2}$ pins with number of cycles after tests under the specified conditions at (a) room temperature, (b) $150^{\circ} \mathrm{C}$, and (c) $250^{\circ} \mathrm{C}$. The number at the end of each curve was the nominal bearing pressure ( $\mathrm{MPa})$ at the end of test. 


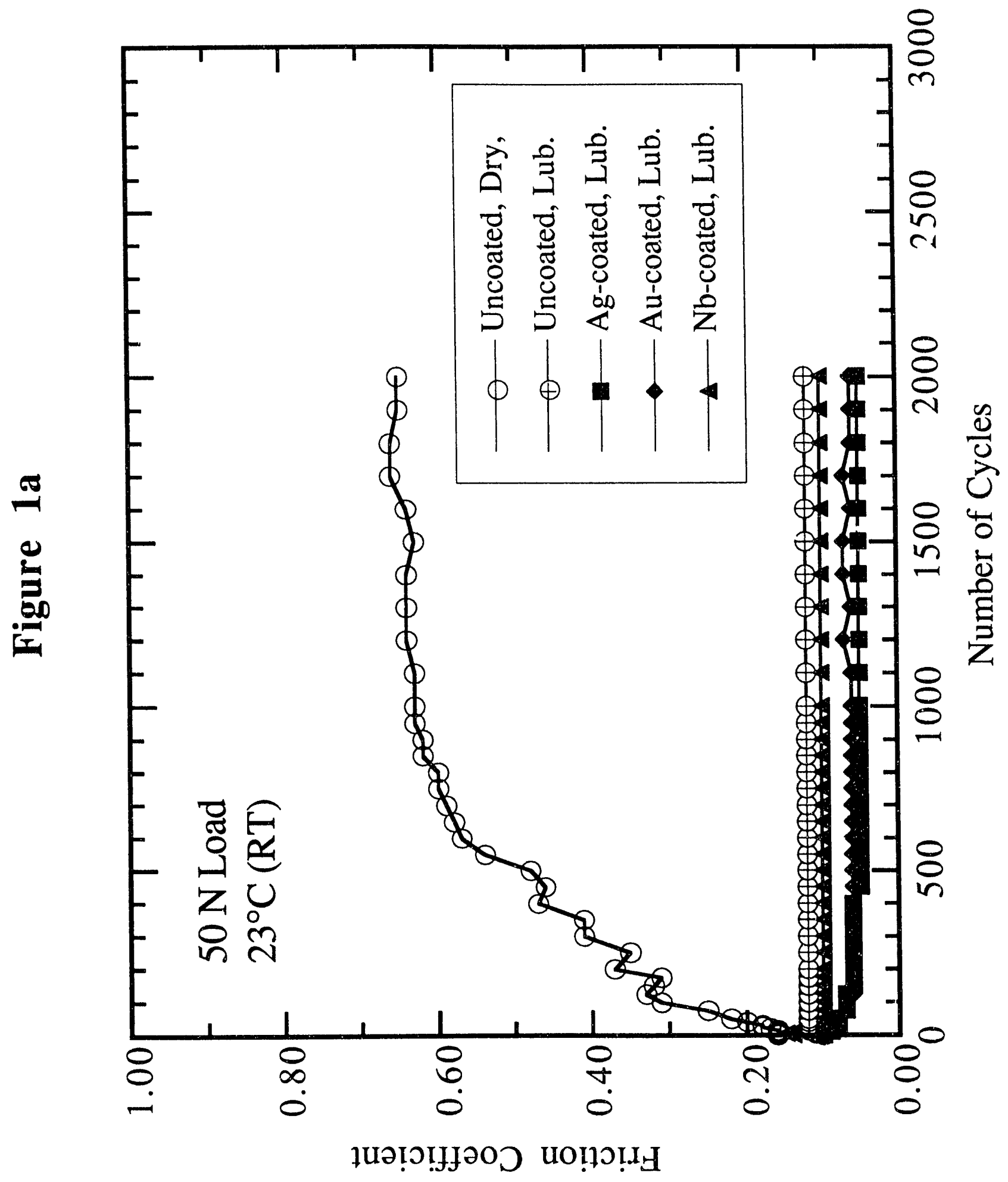




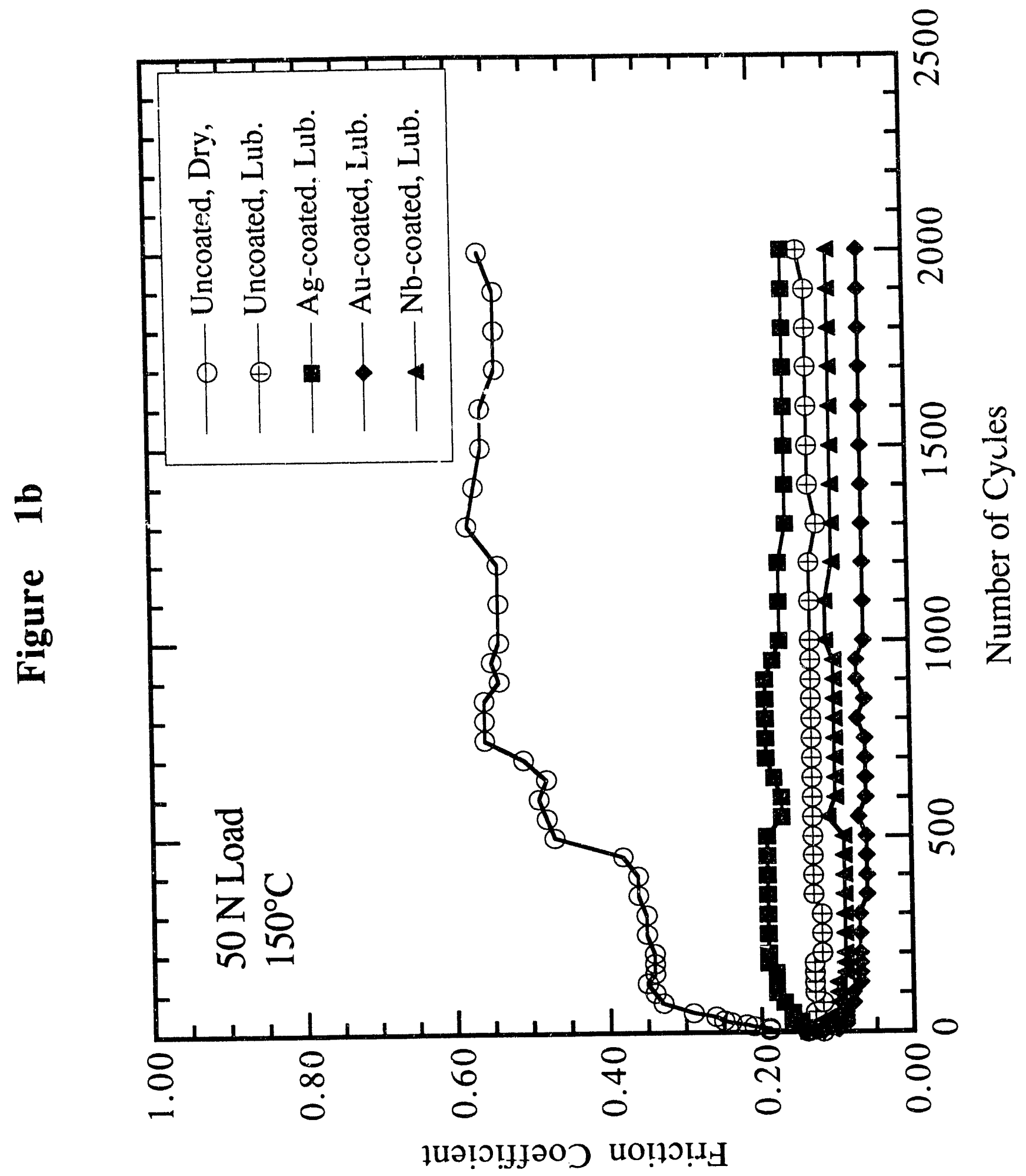




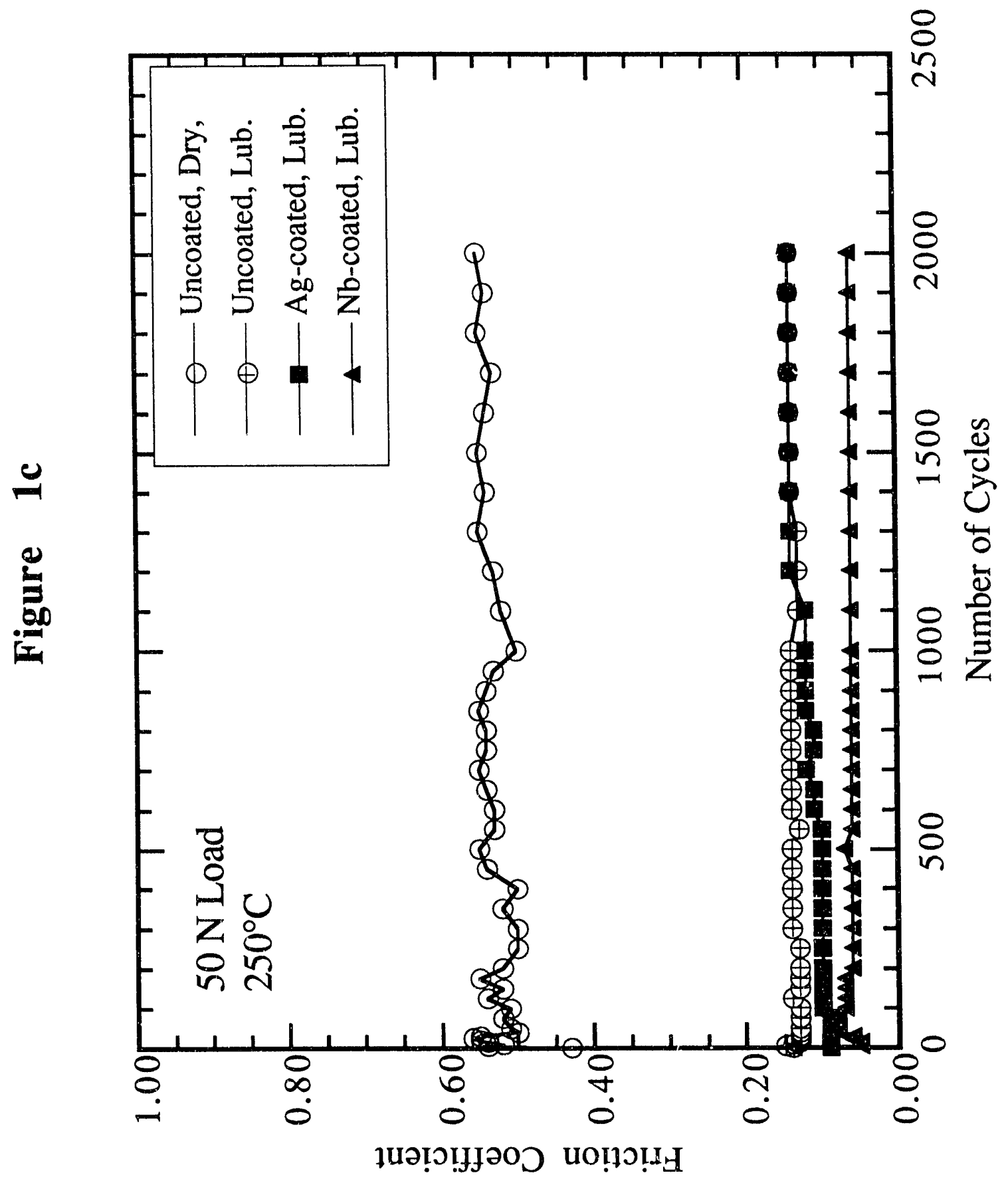




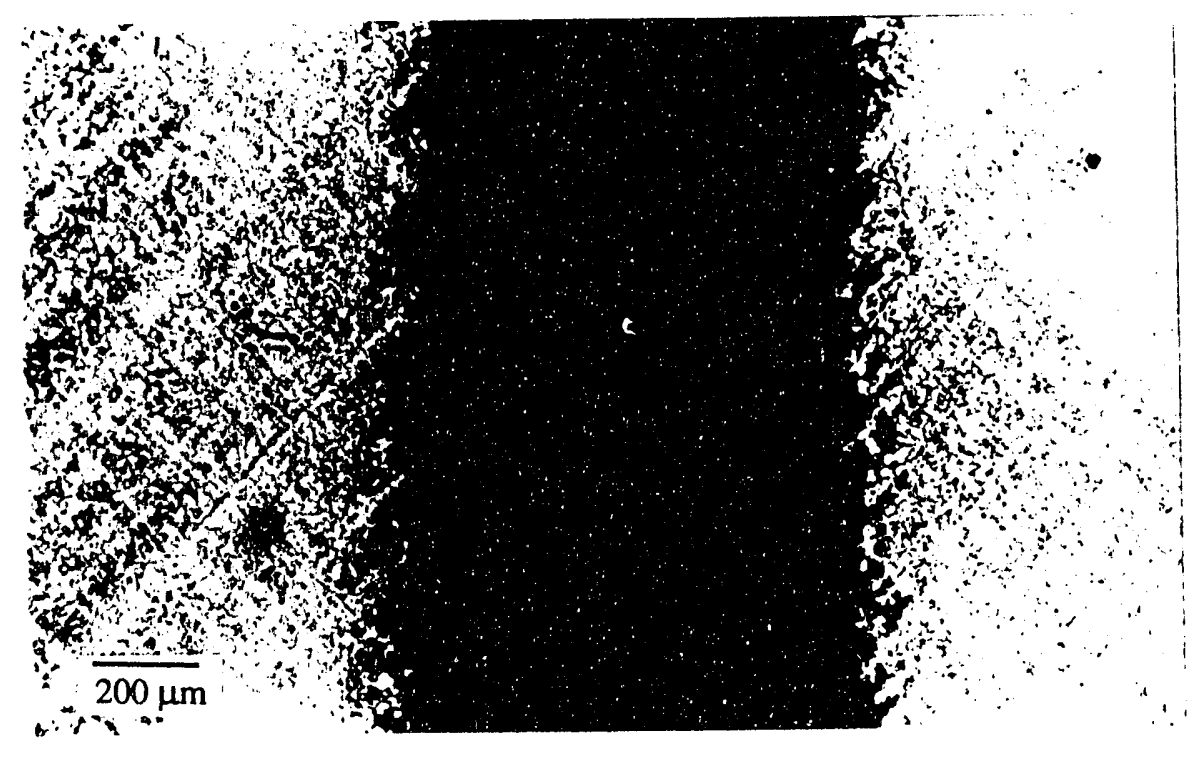

Figure 2 


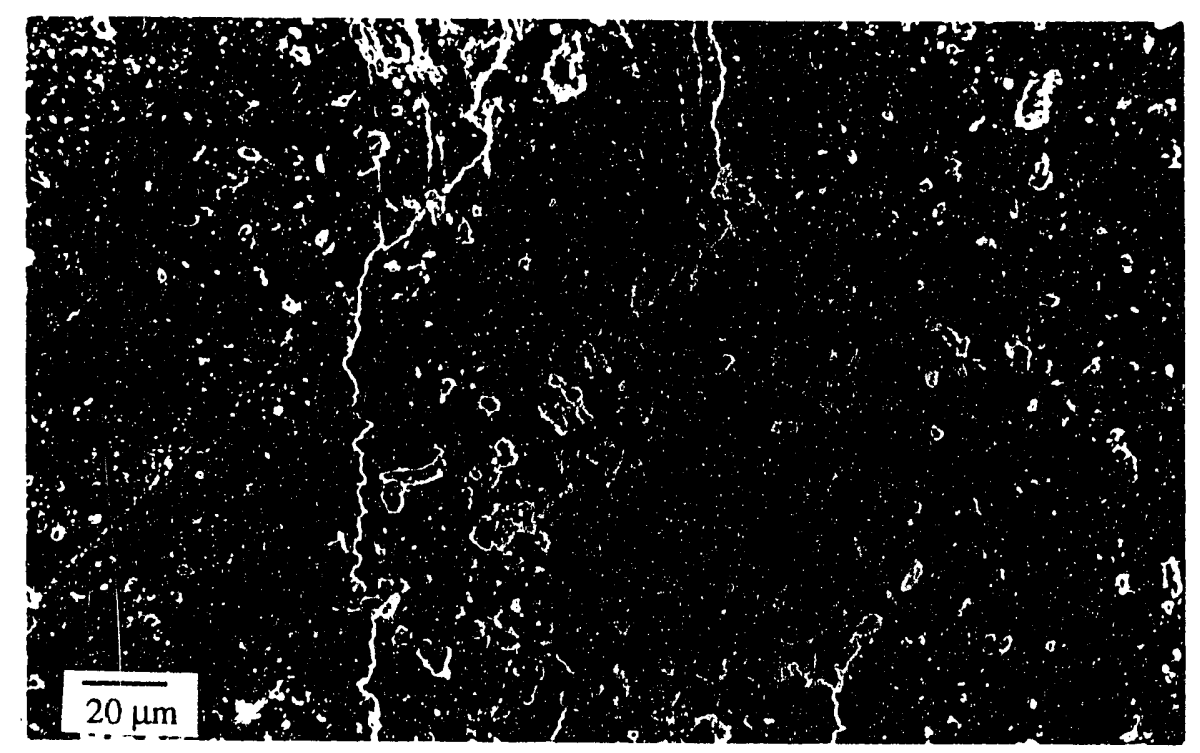

(a)

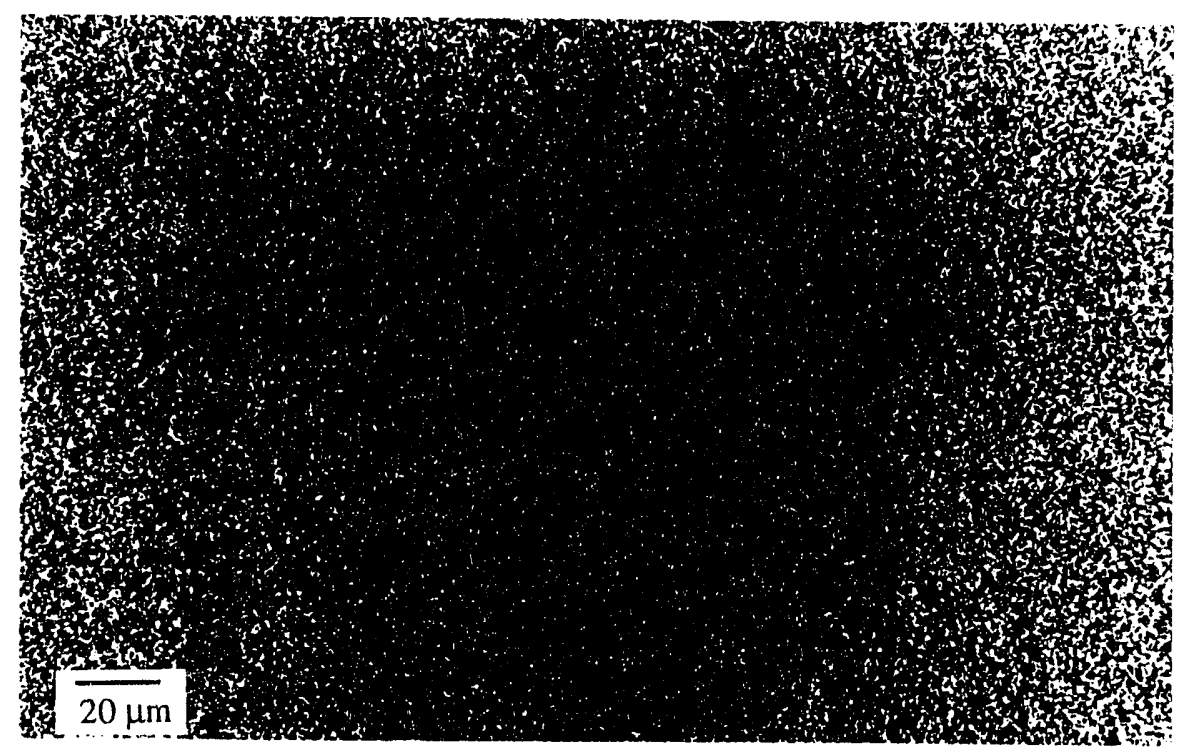

(b)

Figure 3 


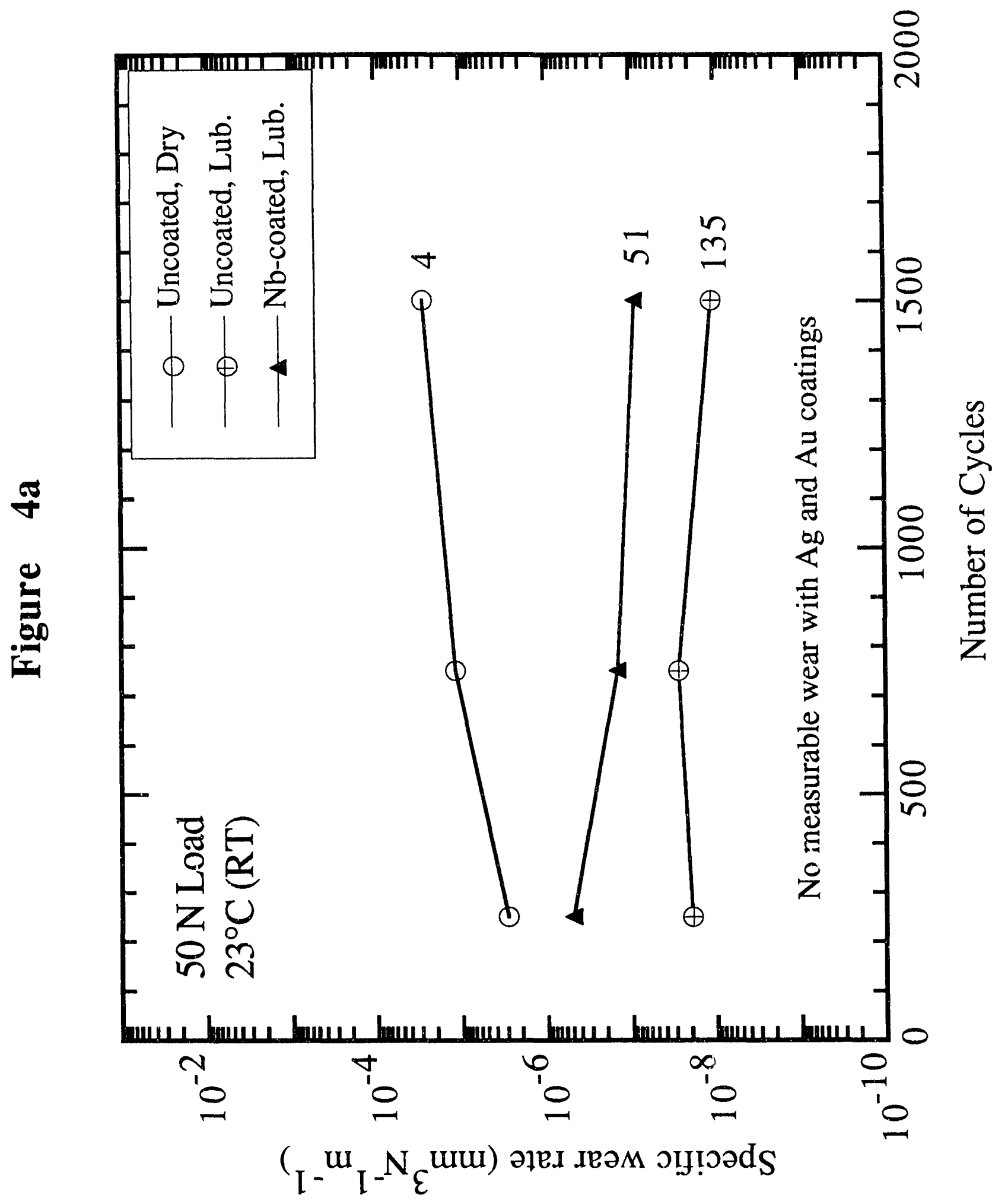




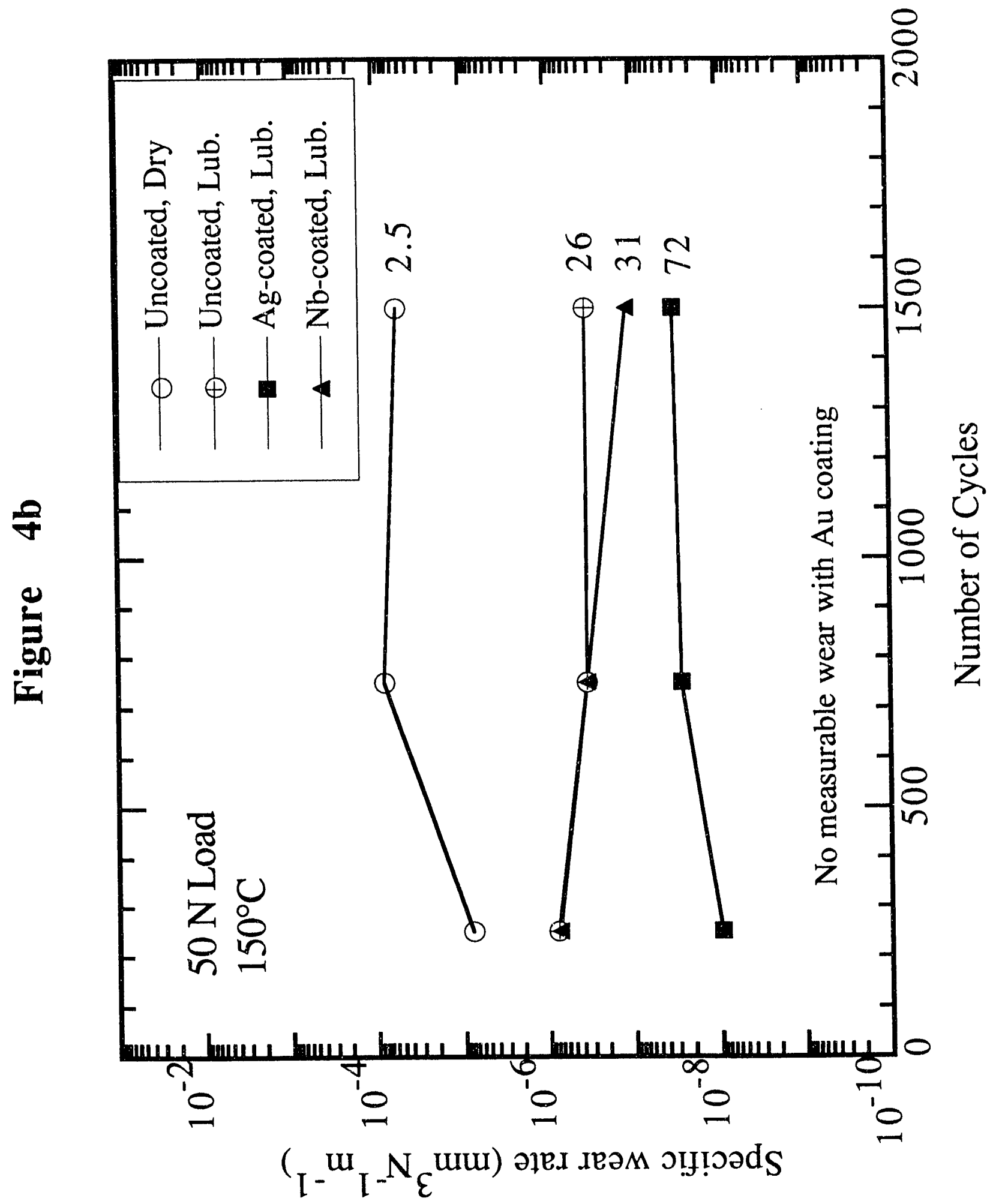




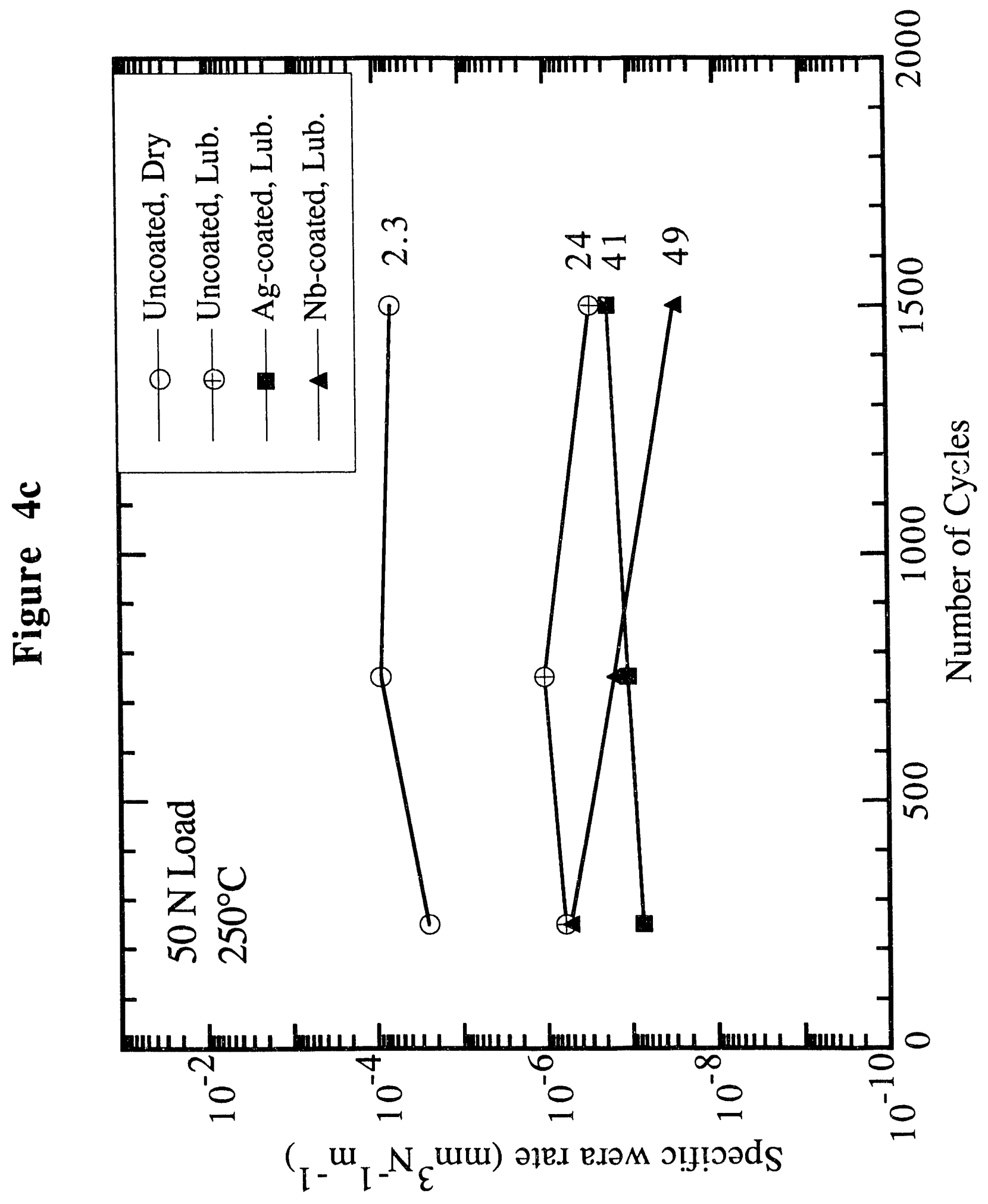



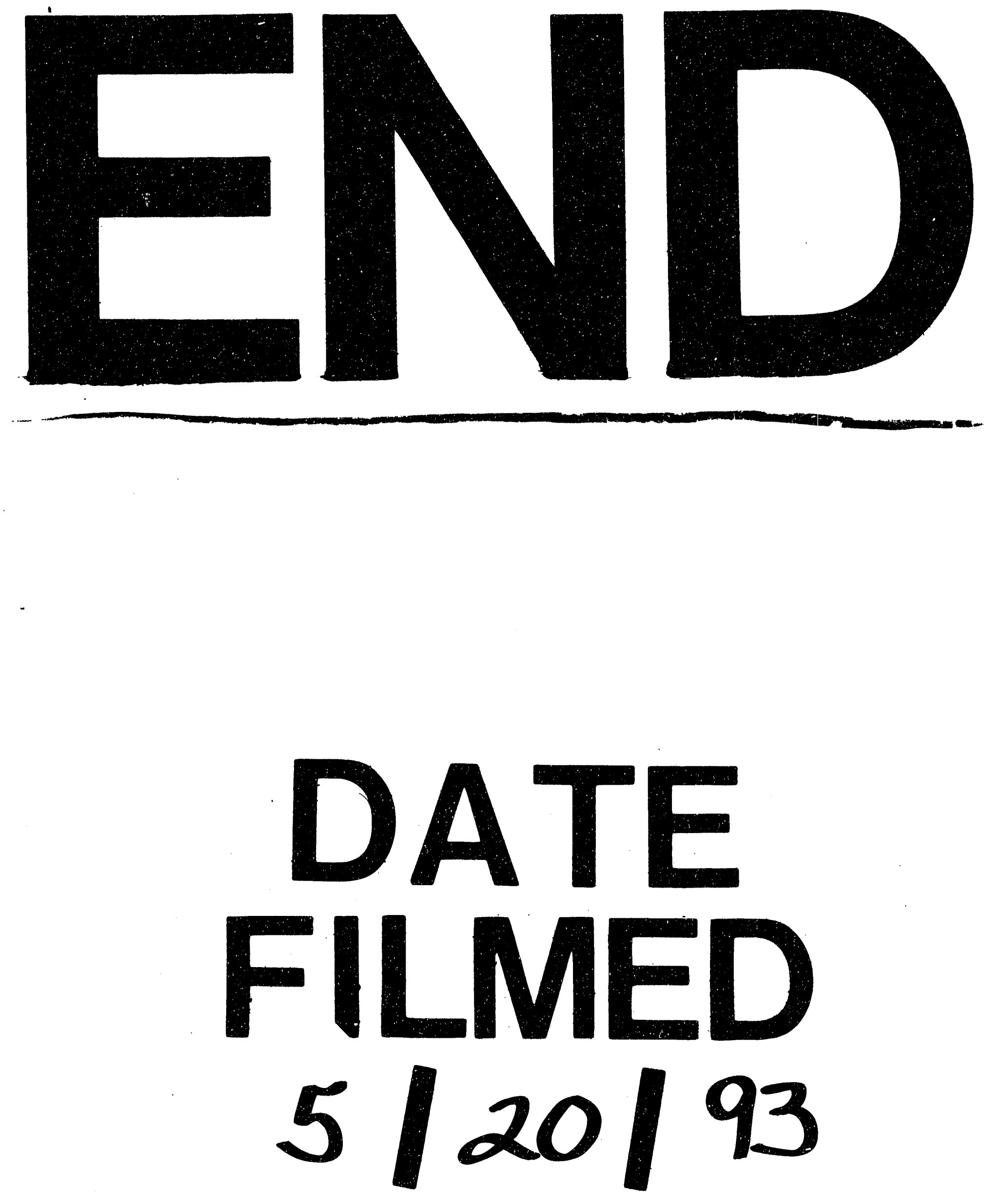
